\title{
Cognitive behavioural therapy (CBT) with exercise led to higher levels of continuous smoking cessation in women than did CBT without exercise
}

Marcus BH, Albrecht AE, King TK, et al. The efficacy of exercise as an aid for smoking cessation in women. A randomized controlled trial. Arch Intern Med 1999 Jun 14;159:1229-34.

QUESTION: Among sedentary female smokers, is regular vigorous exercise effective in facilitating short and long term smoking cessation?

Design

Randomised (unclear allocation concealment*), unblinded*, controlled trial with 12 months of follow up.

\section{Setting}

The Miriam Hospital, Providence, Rhode Island, USA.

\section{Patients}

281 healthy, sedentary women aged $18-65$ years (mean age 40 y) who had regularly smoked $\geqslant 10$ cigarettes a day for $\geqslant 3$ years and who had exercised $<2$ times a week for $\geqslant 6$ months. Exclusion criteria were current or planned use of nicotine replacement therapy, medical problems, current psychiatric illness, alcohol abuse, or another substance abuse problem.

\section{Intervention}

134 women were allocated to a 12 session cognitive behavioural smoking cessation programme with 12 weeks of vigorous exercise and 147 were allocated to the same smoking cessation programme but with equal staff contact time in the form of health education lectures rather than vigorous exercise.

\section{Main outcome measure}

Abstinence from smoking based on self report verified by saliva cotinine level.

\section{Main results}

Analysis was by intention to treat. Compared with the control group, women in the exercise group achieved higher levels of continuous abstinence at the end of treatment $(\mathrm{p}=0.03)$ and at 3 months of follow up $(\mathrm{p}=0.03)$ (table). This outcome was of borderline statistical significance at 12 months of follow up $(p=0.052)$ (table).

Cognitive behavioural smoking cessation programme with vigorous exercise (exercise group) v the same smoking cessation programme with health education (control group) $\dagger$

\begin{tabular}{|c|c|c|c|c|}
\hline Outcomes & $\begin{array}{l}\text { Exercise } \\
\text { group }\end{array}$ & $\begin{array}{l}\text { Control } \\
\text { group }\end{array}$ & $\begin{array}{l}\text { RBI } \\
(95 \% \mathrm{CI})\end{array}$ & $\begin{array}{l}\text { NNT } \\
\text { (Cl) }\end{array}$ \\
\hline $\begin{array}{l}\text { Continuous } \\
\text { abstinence } \\
\text { at end of } \\
\text { treatment }\end{array}$ & $19 \%$ & $10 \%$ & $\begin{array}{l}90 \% \\
\text { (7 to 242) }\end{array}$ & $\begin{array}{l}11 \\
\text { (6 to } 106)\end{array}$ \\
\hline $\begin{array}{l}\text { Continuous } \\
\text { abstinence } \\
\text { at } 3 \\
\text { months }\end{array}$ & $16 \%$ & $8 \%$ & $\begin{array}{l}101 \% \\
(5 \text { to } 287)\end{array}$ & $\begin{array}{l}13 \\
\text { (7 to } 158)\end{array}$ \\
\hline $\begin{array}{l}\text { Continuous } \\
\text { abstinence } \\
\text { at } 12 \\
\text { months }\end{array}$ & $12 \%$ & $5 \%$ & $\begin{array}{l}119 \\
(-0.5 \text { to } 387)\end{array}$ & $\begin{array}{l}\text { Not } \\
\text { significantł }\end{array}$ \\
\hline
\end{tabular}

article. $\neq \mathrm{p}=0.052$

\section{Conclusion}

In healthy, sedentary female smokers, a cognitive behavioural smoking cessation programme with vigorous exercise led to higher levels of continuous smoking cessation than did the same programme without vigorous exercise. *See glossary.

\section{COMMENTARY}

One of the holy grails in smoking cessation is an intervention that eliminates the weight gain associated with stopping. Weight gain and life stress are common reasons for relapse to smoking. ${ }^{1}$ Because exercise has been a useful tool for weight management and stress reduction, Marcus et al conducted a randomised controlled trial to assess the usefulness of exercise for smoking cessation.

This study reports the results of an "efficacy" study that asks the question of whether a supervised exercise programme can assist smoking cessation in a "best case scenario," not whether an exercise programme assists smoking cessation in a clinical practice setting (an "effectiveness" study). In this well designed controlled trial, motivated smokers were randomised to either an exercise programme or a health education programme which met 3 times each week for 12 weeks. All patients received a 12 session group cognitive behavioural smoking cessation programme with a stop date designed especially for women. The exercise group had greater success in stopping smoking than the control group, and the magnitude of effect was comparable to what would be expected with a $21 \mathrm{mg} / 24$ hour nicotine patch combined with minimal behavioural counselling. The group of exercisers who remained abstinent had a statistically significant lower weight gain at 3 months than control patients, but this reduction in weight gain was no longer present 3 months after the intervention was stopped.

Considering our other options for smoking cessation, should we counsel our clients to start an exercise programme to assist in stopping smoking? Yes, if the client is likely to adopt such a programme. The weight and stress management benefits, however, will probably not be sustained unless exercising becomes a long term lifestyle change. ${ }^{2}$ Recommending that smokers join a fitness club or community health group may be helpful. If the likelihood of maintaining an exercise programme is low, then we would consider other effective treatments for smoking cessation.

William S Yancy, MD

Eric C Westman, MD, MHS Duke University and Durham VA Medical Centers Durham, North Carolina, USA

1 Fiore MC, Bailey WC, Cohen SJ, et al. Smoking cessation. Clinical practice guideline no 18. Rockville, MD: Agency for Health Care Policy and Research, 1996.

2 Silagy C, Mant D, Fowler G, et al. Nicotine replacement therapy for smoking cessation. (Cochrane Review, latest version 21 May 98). In: Cochrane Library. Oxford: Update Software. 